Bull. Chem. Soc. Ethiop. 2017, 31(3), 457-463.

ISSN 1011-3924

(c) 2017 Chemical Society of Ethiopia and The Authors

Printed in Ethiopia

DOI: http://dx.doi.org/10.4314/bcse.v31i3.9

\title{
A 3D POLYHEDRAL METAL-ORGANIC FRAMEWORK AS DRUG CARRIER FOR CONTROLLABLE RELEASE
}

\author{
En-Hong Zhou ${ }^{1,2 \#}$, Rui Wang ${ }^{3 \#}$, Jian $\mathrm{Wu}^{4}$, Shuo-Wen Qiu ${ }^{3}$, Jian-QiangLiu ${ }^{3 *}$, Hua-Rui Zhong ${ }^{3}$, \\ Hui-Dong Zeng ${ }^{3}$, Jing-Wen $\mathrm{Xu}^{3}$, Jun-Cheng Jin ${ }^{{ }^{*}}$ \\ ${ }^{1}$ Anhui Provincial Laboratory of Biomimetic Sensor and Detecting Technology, West Anhui \\ University, Anhui 237012, China \\ ${ }^{2}$ West Anhui Health Vocational College, Anhui 237012, China \\ ${ }^{3}$ Dongguan Key Laboratory of Drug Design and Formulation Technology, Key Laboratory of \\ Research and Development of New Medical Materials of Guangdong Medical University, \\ School of Pharmacy, Guangdong Medical University, Dongguan, 523808, China \\ ${ }^{4}$ Guangxi Key Laboratory of Chemistry and Engineering of Forest Products, College of \\ Chemistry and Chemical Engineering, Guangxi University for Nationalities, Nanning, Guangxi \\ 530006, China
}

(Received July 14, 2017; Revised December 20, 2017; Accepted December 21, 2017)

ABSTRACT. A new fabrication of $\left\{\left[\mathrm{H}_{3} \mathrm{O}\right]\left[\mathrm{Cu}_{6}(\text { tpta })_{3}(\mathrm{DMA})_{4}(\mathrm{COO})\right] \cdot 12 \mathrm{H}_{2} \mathrm{O} \cdot 7 \mathrm{DMA}\right\}$ (1) was used as a drug vehicle of 5-fluorouracil (5-FU) for drug delivery. The incorporation of the drug 5-FU into the 1 was around 47.3 $\mathrm{wt} \%$ per gram of dehydrated 1. Cargo release behavior and material degradation profile were also investigated under different mdeium. 5-FU is released in a highly controlled and progressive manner with $92 \%$ of the drug release after $96 \mathrm{~h}$ at acidic condition and with $88 \%$ after $96 \mathrm{~h}$ at PBS. In vitro cytotoxicity assays indicated that the 1 possesses no obvious cytotoxicity. The results provide a new avenue for MOFs to be used as potential drug delivery.

KEY WORDS: Drug delivery, Release, Porous MOF

\section{INTRODUCTION}

Metal-organic frameworks (MOFs) have undergone rapid development as functional materials such as catalysts, luminescence materials and magnetic materials [1-2]. Recently, these pharmaceutical scientists and medicinal chemists pay attention to the research of MOFs, looking for medical applications [3]. Férey and co-workers firstly proposed the use of porous MOFs (such as, MIL-100 and MIL-101) as controlled delivery systems [1b]. This method strongly depends on the loading capacity of the porous materials, as well their pore size and conformation [4]. Polyhedral metal-organic frameworks (PMOFs) are different from traditional MOFs, they have cages carrying large voids and open-channel-type pores. Due to the sieving effect, the sizes of windows can make the suitable drug molecules go through the pores [5]. A large number of reported PMOFs exhibit high drug delivery [6-12].

Recently, Liu and his co-worker have successfully prepared a novel $(3,4)$-connected topology PMOF (1) with a schläfli symbol of $\left\{4 \cdot 6^{2} \cdot 8^{3}\right\}\left\{4 \cdot 6^{4} \cdot 8\right\}\left\{4 \cdot 6^{5}\right\}_{4}$ using the super molecular building block (SBB) strategy [13]. It features three types of cages with multiple sizes and shapes and exhibits high performance for $\mathrm{CO}_{2}$ capture and selectivity of $\mathrm{CO}_{2} / \mathrm{CH}_{4}$ and $\mathrm{C}_{3} \mathrm{H}_{8} / \mathrm{CH}_{4}$. Moreover, the Brunauer-Emmett-Teller (BET) surface area for $\mathbf{1}$ is calculated to be

\footnotetext{
\# The authors have equal contribution on this work.

*Corresponding author. E-mail: jcjgd2017@126.com, jianqiangliu2010@126.com

This work is licensed under the Creative Commons Attribution 4.0 International License
} 
$1487 \mathrm{~m}^{2} \mathrm{~g}^{-1}$. The high-porosity together with a multiple-pore system and high-density open metal sites (OMSs) (1.0 per $\mathrm{nm}^{3}$ ) in this PMOF inspired us to investigate its drug molecules uptake capacity. Up to now, only a few MOFs allow high amounts of drug to be stored, with a completed delivery time ranging from 6 to 23 days [14]. We are also particularly interested in the design and synthesis of porous MOFs carriers that have been made to pave their way toward medical applications [5b, 5c, 15]. In this concern, we propose the development of $\mathbf{1}$ as drug carrier, which may exhibit excellent drug loading capacity taking advantage of its larger pore size and permanent porosity. As expected, the incorporation of the drug 5-FU into the 1 was around $47.29 \mathrm{wt} \%$ per gram of dehydrated 1. Furthermore, 5-FU is released in a highly controlled and progressive manner with $92 \%$ of the drug release after $96 \mathrm{~h}$ at acidic condition and with $88 \%$ after $96 \mathrm{~h}$ at PBS.The result from this work provides a new viewpoint for MOF to be used as potential drug delivery.

\section{EXPERIMENTAL}

\section{Materials and methods}

$\mathrm{Cu}\left(\mathrm{NO}_{3}\right)_{2} \cdot 3 \mathrm{H}_{2} \mathrm{O}$ of analytic grade were obtained from Shanghai Chemical Factory, China.5Fluorouracil (5-FU) was purchased from Kemao Biotech Company (Dongguan City, China). All the other chemicals were purchased from Aldrich. All chemicals and solvents were used as received without further purification. The powder X-ray diffraction (PXRD) patterns were measured using a Bruker D8 advance powder diffractometer at $40 \mathrm{kV}$ and $40 \mathrm{~mA}$ for $\mathrm{Cu} \mathrm{K} \alpha$ radiation $(\lambda=1.5418 \AA)$, with a scan speed of $0.2 \mathrm{~s} /$ step and a step size of $0.02^{\circ}(2 \theta)$.

\section{Synthesis of $\left\{\left[\mathrm{H}_{3} \mathrm{O}\right]\left[\mathrm{Cu}_{6}(\text { tpta })_{3}(\mathrm{DMA})_{4}(\mathrm{COO})\right] \cdot 12 \mathrm{H}_{2} \mathrm{O} \cdot 7 \mathrm{DMA}\right\}$}

The synthetic method as that of title compound was followed the reported reference [13] except that DMA was chosen instead of DMA $/ \mathrm{H}_{2} \mathrm{O}$. The detail synthesis was described herein. Single crystal of compound 1 was obtained by solvothermal reaction of $\mathrm{Cu}\left(\mathrm{NO}_{3}\right)_{2} \cdot 3 \mathrm{H}_{2} \mathrm{O}(8 \mathrm{mg} 0.033$ mmol) and $\mathrm{H}_{4}$ tpta $(2 \mathrm{mg}, 0.005 \mathrm{mmol})$ in DMA $\left.(2 \mathrm{~mL}) 0.65 \mathrm{~mL}\right)$ with $\mathrm{HNO}_{3}(0.65 \mathrm{~mL})$ at 105 ${ }^{\circ} \mathrm{C}$ for 24 hours. The mixture was then cooled to room temperature. The final products were obtained and air-dried (yield $45 \%$, based on $\mathrm{H}_{4}$ tpta) [13]. We have used the single crystal data reported previously by Wang et al. [13] and stored at the Cambridge Crystallographic Data Center (CCDC: 1410333) for comparison and data simulation and analysis. The simulated powder patterns were calculated using Mercury 2.0. The purity and homogeneity of the bulk products were determined by comparing the simulated and experimental X-ray powder diffraction patterns. The experimental PXRD pattern is in good agreement with the simulated one based on the single crystal X-ray data, indicating the purity of the as-synthesized product.

Drug loading

To load 5-fluorouracil (5-FU) into the pores of 1, dehydrated samples were dispersed in a 5-FU containing methanol solution $(25 \mathrm{~mL})$ and stirred for different days. The adsorbed amount of 5FU into the porous solids was estimated by UV-Vis absorption spectroscopy at $265 \mathrm{~nm}$. Experiments were performed in quadruplicate and drug payloads 5-FU was calculated according to the following formula:

$5-\mathrm{FU}=5-\mathrm{FU}(\mathrm{mg}) /$ dehydrated materials $(\mathrm{mg}) \times 100 \%$

Drug release

Amount of inclusions were loaded into a dialysis bag $(\mathrm{MWCO}=1000)$, which were dialyzed against $500 \mathrm{~mL}$ of PBS buffer solution at room temperature. During each time interval, $1 \mathrm{~mL}$ of 
solution was taken out, and $1 \mathrm{~mL}$ of fresh PBS buffer was added. The content of 5-FU in the samples taken out was determined by HPLC.

\section{RESULTS AND DISCUSSION}

1 has three types of cages with different sizes (10 (cage A), 13 (cage B), and $18 \AA$ (cage C), respectively). The smallest cage $\mathrm{A}$ contains $12 \mathrm{Cu}$ paddle wheel units and 6 tpta $^{4-}$ linkers to construct a truncated tetrahedron shape (Figure 1a); the medium cage B with cuboctahedron geometry comprises of $12 \mathrm{Cu}$ paddle wheel units and 24 tpta $^{4-}$ linkers (Figure $1 \mathrm{~b}$ ); and the largest cage $\mathrm{C}$ presents a truncated octahedron included $24 \mathrm{Cu}$ paddle wheel MBBs and 16 tpta $^{4-}$ linkers (Figure 1c). The three types of polyhedron packing arrangements result in a 3D network with a multiple pore system (Figure 1d).

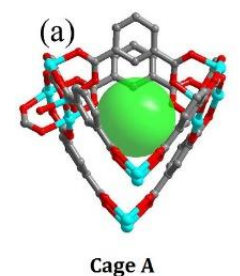

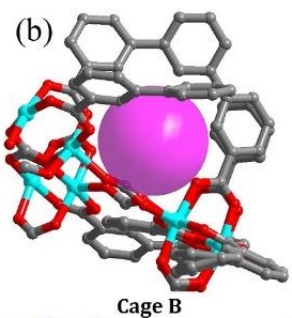

(d) (c)

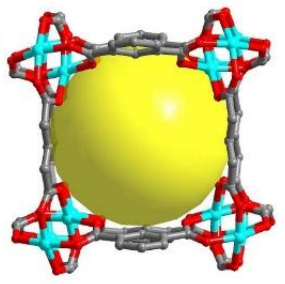

Cage C

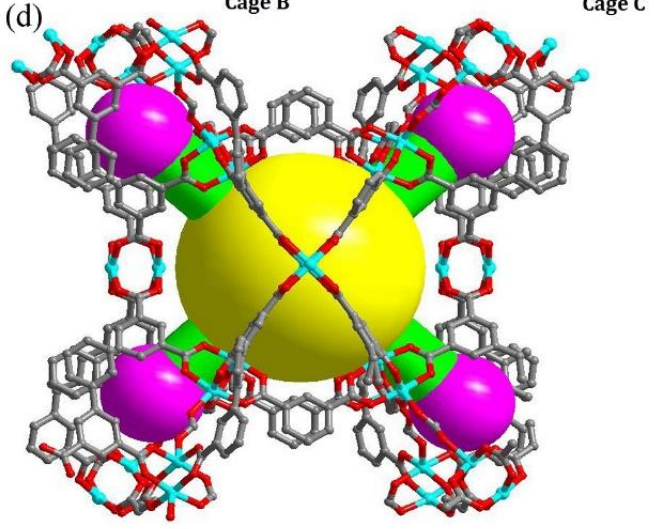

Figure 1. Description of the structure of 1: (a)-(c) three types of cages with different sizes (diagonal $\mathrm{Cu}-\mathrm{Cu}$ distance, regardless of vander Waals radii), the sizes of inner balls are $10 \AA$ (cage A), $13 \AA$ (cage B) and $18 \AA$ (cage C), respectively; (d) ball and stick model of the $3 \mathrm{D}$ framework.

5-FU was selected because of its size, which was small enough to be incorporated into the cavity of 1. The stabilities of 1 and 1 @5-FU are confirmed by IR and PXRD. UV-Vis absorption spectroscopy has been used to determine the effective storage capacity of $\mathbf{1}$. To gain a maximal drug loading, 5-FU to porous solid relative ratio and contact time were tested. After the trivial tests, the best results were achieved when 1 was soaked for 3 days in a $20 \mathrm{~mL}$ ethanol solution with a 5 -FU to 1 weight ratio of $1: 1$. It showed 5-FU adsorption and the loading content was measured to be $47.3 \%$. This result is higher to 5-FU adsorbed by MOP-15 [16]. There is 
almost no $\mathrm{N}_{2}$ sorption after the encapsulation of 5-FU, indicating that the drug completely fills the pores or blocks the windows of the inner space. The ionic framework and open metal sites enhance framework-drug interactions through weak forces, which may affect the loading capacity and the moment of $\mathrm{N}_{2}$.

As is well known, compared to tumor tissues, the $\mathrm{pH}$ in normal tissues is slightly higher. To study 5-FU release of 1 under physiological and low $\mathrm{pH}$ condition, drug release experiments were carried out by dialyzing the drug-loaded 1 in phosphate buffer $(\mathrm{pH}=6.0)$ and $\mathrm{PBS}(\mathrm{pH}=$ 7.4) at $37{ }^{\circ} \mathrm{C}$, respectively. The delivery of 5-FU occurred within a week with continuous stirring and the delivered 5-FU concentration was determined. As can be seen from Figure $2 \mathrm{a}$, the comparison of kinetics of drug delivery between different $\mathrm{pH}$ solutions $(\mathrm{pH} 6.0$ and $\mathrm{pH} 7.4)$ suggests that the delivery process of 5-FU@1 is pH-responsive, rendering this pH-driven release can be used to tumor therapy. Indeed, 5-FU is released in a highly controlled and progressive manner with $92 \%$ of the drug release after $96 \mathrm{~h}$ at acidic condition and with $88 \%$ after $96 \mathrm{~h}$ at PBS. From the Figure $2 \mathrm{a}$, around $48 \%$ and $71 \%$ of the loaded drug was detected in the acidic buffer and PBS during the initial stage $(24 \mathrm{~h})$, respectively. Then, after $40 \mathrm{~h}$, a much burst release was occurred. This slightly fast-release may result from the degradation of the structure, which was accordance to in vitro degradation profile. The degradation profile (Figure $2 b$ ) displays that the solids of 1 can be degraded around $35 \%$ and $21 \%$ at phosphate buffer $(\mathrm{pH}=6)$ and PBS after $24 \mathrm{~h}$, respectively, indicating a reasonable in vitro degradability. However, the comparison between the drug release kinetic and degradation of $\mathbf{1}$, which cannot degrade entirely even in two different environments, showed that the delivery process is not governed by the MOF degradation [17].

(a)

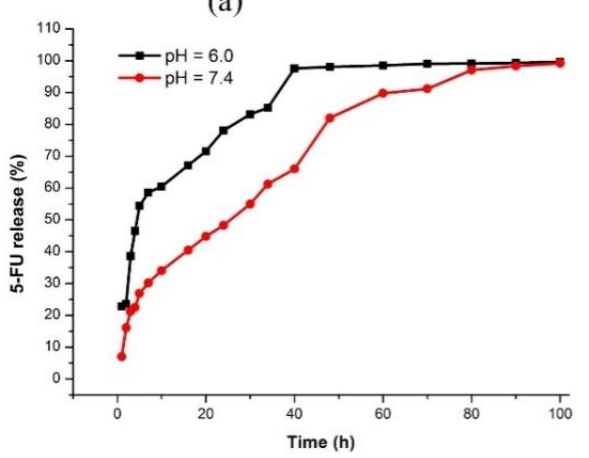

(b)

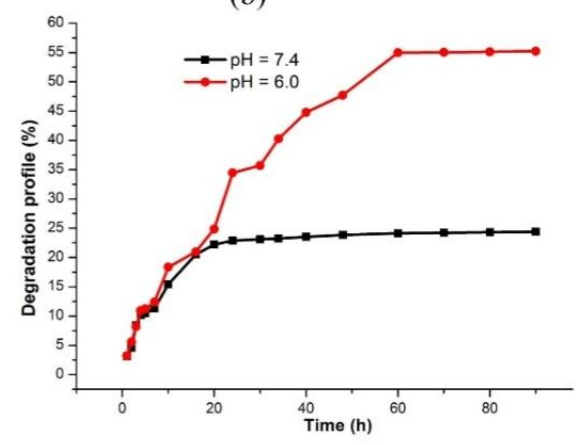

Figure 2. (a) The release process of 5-FU from the drug-loaded 1 and (b) the degradation profile of 1.

In order to preliminary assess their anticancer efficacies. The vitro toxicity analysis was conducted by MTT assay later due to compatibility and cytotoxicity are extraordinarily significant for MOFs in medicine science. The samples of L, 1 and $1 @$ drug were arranged from the concentration of $0-30 \mu \mathrm{g} \mathrm{mL}^{-1}$. Interestingly, Figure 1 presents that both Hek293 and HeLa cells were non invasive (the cell viability is above $80 \%$ ) treating with Land $\mathbf{1}$, which imply that $\mathrm{L}$ and 1 had no effect on human normal or tumor cells (Figure 3). And 1@drug made dramatic impact on HeLa and has vastly altered the cell viability. It meant that 1 loading drug possesses a potent antic-tumor activity and is expected to be a powerful neoplasm suppression drug in the future [18-19]. 

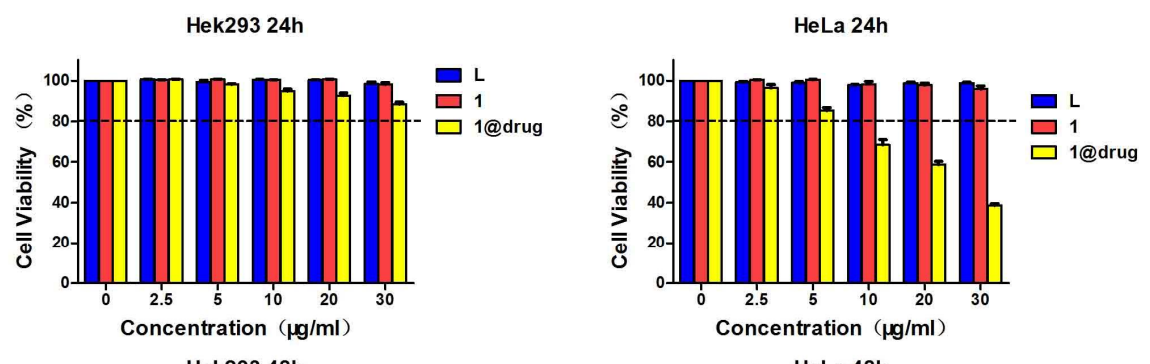

Hek293 48h

HeLa 48h
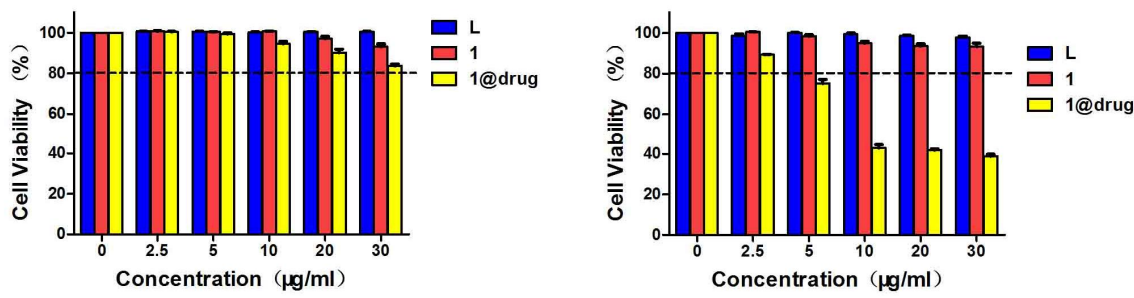

Hek293 72h

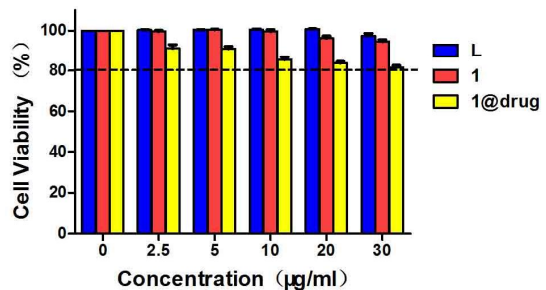

HeLa 72h

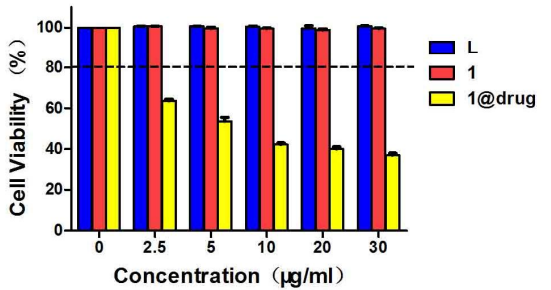

Figure 3. MTT cytotoxicity assay of HepG2 and HeLa cells treated with 1 and 1@5-FU at various concentrations $(n=5$, date are the mean $\pm S D)$.

\section{CONCLUSION}

In summary, we selected and conducteda PMOF as a drug carrier that shows a higher drug loading capacity, controllable cargo release and low cytotoxicity, which may be a promising candidate of drug delivery systems for cancer therapy.

\section{ACKNOWLEDGEMENTS}

This work was partially supported by the grants from NSF of China (21701033 and 21401143), the Science and Technology Plan Projects of Dongguan (2016108101005), Science Foundation funded project of Guangdong Medical University (Z2016001 and M2016023), Innovative Entrepreneurial Training Plan of undergraduatesin Guangdong Province(201710571005, 201710571007; 201710571012; 201710571016; 201710571008; 201710571020, 201710571060), Guangxi Natural Science Foundation (No. 2016GXNSFAA380063) and the Excellent Young Support Program of Anhui Province (gxyqZD20170735). 


\section{REFERENCES}

1. (a) Wang, H.; Hu, T.L.; Wen, R.M.; Wang, Q.; Bu,X.H. In vitro controlled release of theophylline from metal-drug complexes. J. Mater. Chem. B 2013, 32, 3879-3882; (b) Horcajada, P.; Serre, C.; Vallet-Regí, M.; Sebban, M.; Taulelle, F.; F'erey, G. Metal-organic frameworks as efficient materials for drug delivery. Angew. Chem., Int. Ed. 2006, 118, 6120-6124.

2. (a) Miller, S.R.; Heurtaux, D.; Baati, T.; Horcajada, P.; Greneche, J.-M.; Serre, C. Biodegradable therapeutic MOFs for the delivery of bioactive molecules. Chem. Commun. 2010, 46, 4526-4528; (b) Gianluca, M.; Erika, F.; Gigliola, L.; Valentina, A.; Francesca, F.; Claudio, M.; Francesca, P.; Monica, S.; Ledi, M. The role of coordination chemistry in the development of innovative gallium-based bioceramics: The case of curcumin. J. Mater. Chem. 2011, 21, 5027-5037; (c) Vasconcelos, I.B.; Silva, T.G.; Militao, G.C.G.; Soares, T.A.; Rodrigues, N.M.; Rodrigues, M.O.; Costa, N.B.; Freire, R.O.; Junior, S.A. Cytotoxicity and slow release of the anti-cancer drug doxorubicin from ZIF-8. RSC Adv. 2012, 25, 9437-9442; (d) Roushani, M.; Baghelani, Y.M.; Abbasi, S.; Mohammadi, S.Z.; Mavaei, M. Solid phaseextraction of trace amounts of zinc and cadmium ions using perlite as a supper sorbent. Bull. Chem. Soc. Ethiop. 2016, 30, 175-184; (e) Esmaielzadeh, S.; Zare, Z.; Azimian, L. Synthesis, physical characterization, antibacterialactivity and thermodynamic studies of five coodrdinate cobalt(III) Schiff base complexes. Bull. Chem. Soc. Ethiop. 2016, 30, 209-220; (f) Assefa, Z.; Gore, S.B. Structural and spectroscopic studies of 2,9-dimethyl-1,10-phenanthrolinium cation (DPH) with chloride, triflate and gold dicyanide anions. The role of H-bonding in molecular recognition and enhancement of $\pi-\pi$ stacking. Bull. Chem. Soc. Ethiop. 2016, 30, 231-239.

3. (a) Ma, Z.; Moulton, B. Recent advances of discrete coordination complexes and coordination polymers in drug delivery. Coord. Chem. Rev. 2011, 255, 1623-1641; (b) Taylor, K.M.L.; Jin, A.; Lin, W. Surfactant assisted synthesis of nanoscale gadolinium metal-organic frameworks for potential multimodal imaging. Angew. Chem., Int. Ed. 2008, 120, 7836-7839; (c) Giménez-Marqués, M.; Hidalgo, T.; Serre, C.; Horcajada, P.; Nanostructured metal-organic frameworks and their bio-related applications. Coord. Chem. Rev. 2016, 307, 342-360.

4. Sun, C.Y.; Qin, C.; Wang, C.G.; Su, Z.M.; Wang, S.; Wang, X.L.; Yang, G.S.; Shao, K.Z.; Lan, Y.Q.; Wang, E.B. Chiral nanoporous metal-organic frameworks with high porosity as materials for drug delivery. Adv. Mater. 2011, 23, 5629-5632.

5. (a) Horcajada, P.; Gref, R.; Baati, T.; Allan, P.K.; Maurin, G.; Couvreur, P.; Férey, G.; Morris, R.E.; Serre, C. Metal-organic frameworks in biomedicine. Chem. Rev. 2012, 112, 1232-1268; (b) Liu, J.; Li, X.; Gu, C.; Da Silva, J.C.S.; Barros, A.L.; Alves-Jr, S.; Li, B.; Ren, F.; Batten, S.R.; Soares, T.A. A combined experimental and computational study of novel nanocage-based metal-organic frameworks for drug delivery. Dalton Trans. 2015, 44, 19370-19382; (c) Liu, J.; Wu, J.; Jia, Z.; Chen, H.; Daiguebonne, C.; Guillou, O.; Sakiyama, H.; Soares, T.; Ren, F.; Ng, S.W.; Li, Q. Two isoreticular metal-organic frameworks with $\mathrm{CdSO}_{4}$-like topology: Selective gas sorption and drug delivery. Dalton Trans. 2014, 43, $17265-17273$.

6. Rieter, W.J.; Pott, K.M.; Taylor, K.M.L.; Lin, W. Nanoscale coordination polymers for platinum-based anticancer drug delivery. J. Am. Chem. Soc. 2008, 130,11584-11585.

7. Lin, W.; Rieter, W.J.; Taylor, K.M.L. Modular synthesis of functional nanoscale coordination polymers. Angew. Chem., Int. Ed. 2009, 48, 650-658.

8. Luisi, B.S.; Rowlanda, K.D.; Moulton, B. Coordination polymer gels: Synthesis, structure and mechanical properties of amorphous coordination polymers. Chem. Commun. 2007, 27, 2802-2804. 
9. Chalati, T.; Horcajada, P.; Couvreur, P.; Serre, C.; Ben Yahia, M.; Maurin, G.; Gref, R. Porous metal organic framework nanoparticles to address the challenges related to busulfan encapsulation Nanomed. 2011, 6, 1683-1695.

10. Anand, R.; Borghi, F.; Manoli, F.; Manet, I.; Agostoni, V.; Reschiglian, P.; Gref, R., Monti, $\mathrm{S}$. Host-guest interactions in Fe(III)-trimesate MOF nanoparticles loaded with doxorubicin, J. Phys. Chem. B. 2014, 118, 8532-8539.

11. (a) Vasconcelos, I.B.; da Silva, T.G.; Militao, G.C.G.; Soares, T.A.; Rodrigues, N.M.; Rodrigues, M.O.; da Costa Jr., N.B.; Freire, R.O.; Junior, S.A. RSC Adv. 2012, 2, 94379442; (b) Ren, H.; Zhang, L.; An, J.; Wang, T.; Li, L.; Si, X.; He, L.; Wu, X.; Wang, C.; Su, Z.; Polyacrylic acid@ zeoliticimidazolate framework-8 nanoparticles with ultrahigh drug loading capability for $\mathrm{pH}$-sensitive drug release. Chem. Commun. 2014, 50, 1000-1002.

12. Bellido, E.; Hidalgo, T.; Lozano, M.V.; Guillevic, M.; Simon-Vazquez, R.; SantanderOrtega, M.; Gonzalez-Fernandez, J.A.; Serre, C.; Alonso, M.J.; Horcajada, P. Heparinengineered mesoporous iron metal-organic framework nanoparticles: Toward stealth drug nanocarriers. Adv. Health. Mater. 2015, 4,1246-1257.

13. Wang, D.; Liu, B.; Yao, S.; Wang, T.; Li, G.; Huo, Q.; Liu, Y. A polyhedral metal-organic framework based on the supermolecular building block strategy exhibiting high performance for carbon dioxide capture and separation of light hydrocarbons. Chem. Commun. 2015, 51, $15287-15289$.

14. Millange, F.; Medina, M.; Guillou, N.; Férey, G.; Golden, K.M.; Walton, R.I. Timeresolved in situ diffraction study of the solvothermal crystallization of some prototypical metal-organic frameworks. Angew. Chem. Int. Ed. 2010, 49, 763-766.

15. (a) Li, F.M.; Li, B.H.; Wang, C.F.; Zeng, Y.P.; Liu, J.Q.; Gu, C.Y.; Lu, P.F.; Mei, L. Encapsulation of pharmaceutical ingredient linker in metal-organic framework: combined experimental and theoretical insight into the drug delivery. RSC Adv. 2016, 6, 47959-47965; (b) Wang, J. P.; Jin, J.C.; Li, F.M.; Li, B.H.; Liu, J.Q.; Jin, J.; Wang, C.F.; Zeng, Y.P.; Wang, Y.K. Combined experimental and theoretical insight into the drug delivery of nanoporous metal-organic frameworks. RSC Adv. 2015, 5, 85606-85612.

16. Wang, H.; Meng, X.; Yang, G.; Wang, X.; Shao, K.; Su, Z.; Wang, C. Stepwise assembly of metal-organic framework based on a metal-organic polyhedron precursor for drug delivery. Chem. Commun. 2011, 47, 7128-7130.

17. (a) Della Rocca, J.; Liu, D.; Lin, W. Nanoscale metal-organic frameworks for biomedical imaging and drug delivery. Acc. Chem. Res. 2011, 44, 957-968; (b) Zhao, D.; Tan, S.; Yuan, D.; Lu, W.; Rezenom, Y.H.; Jiang, H.; Wang, L.; Zhou, H. Surface functionalization of porous coordination nanocages via click chemistry and their application in drug delivery. Adv. Mater. 2011, 23, 90-93.

18. Zhao, H.X.; Zou, Q.; Sun, S.K.; Yu, C.S.; Zhang, X.J.; Li, R.J.; Fu, Y.Y. Theranostic metalorganic framework core-shell composites for magnetic resonance imaging and drug delivery. Chem. Sci. 2016, 7, 5294-5301.

19. Li, L.; Wu, Y. Q.; Sun, K.K.; Zhang, R.; Fan, L.; Liang, K.K.; Mao, L.B. Controllable preparation and drug loading properties of core-shell microspheres $\mathrm{Fe}_{3} \mathrm{O}_{4} @ \mathrm{MOFs} / \mathrm{GO}$, Mater. Lett. 2016, 162, 207-210. 